\title{
EXCLUSIVE BREASTFEEDING, COMPLEMENTARY FEEDING, LOW BIRTHWEIGHT, AND WASTING IN CHILDREN UNDER-FIVE: A PATH ANALYSIS EVIDENCE FROM INDONESIA
}

\author{
IKA YULI AYUNINGRUM ${ }^{1 *}$, BHISMA MURTI ${ }^{1}$, HARSONO SALIMO ${ }^{2}$, YULIA LANTI RETNO DEWI ${ }^{3}$
}

\begin{abstract}
${ }^{1}$ Masters Program in Public Health, Graduate School, Universitas Sebelas Maret, Surakarta, Indonesia. ${ }^{2}$ Department of Pediatrics, Dr. Moewardi Hospital, Faculty of Medicine, Universitas Sebelas Maret, Surakarta, Indonesia. ${ }^{3}$ Department of Nutrition, Faculty of Medicine, Universitas Sebelas Maret, Surakarta, Indonesia. Email: ayuningrum0811@gmail.com
\end{abstract}

Received: 22 June 2018, Revised and Accepted: 24 July 2018

ABSTRACT

Objective: Studies using life course perspective, longitudinal data, and path analysis on the relationships between exclusive breastfeeding (EBF), complementary feeding (CF), low birthweight (LBW), and wasting are lacking. This study aimed to investigate the relationships between EBF, CF, LBW, and wasting, while controlling for some confounding factors.

Methods: This was a case-control study conducted in Purworejo, Central Java, Indonesia. A total sample of 160 children 2-5 years of age were selected by fixed disease sampling, consisting of 28 wasted and 132 normal weight children. The dependent variable was wasting. The independent variables were EBF, CF, LBW, maternal middle upper-arm circumference at pregnancy, and family income at pregnancy. Sources of data were maternal and child health record and pre-tested questionnaire. The data were analyzed by path analysis using Stata 13.

Results: A path model was created based on life course perspective and longitudinal sample data. Wasting was directly and significantly affected by $\mathrm{CF}(\mathrm{b}=-3.65 ; 95 \% \mathrm{CI}=-5.72--1.59 ; \mathrm{p}<0.001)$. The direct association between wasting and EBF was not significant $(\mathrm{b}=0.37 ; 95 \% \mathrm{CI}=-0.76-1.49$; $\mathrm{p}=0.521)$, while the indirect association between wasting and EBF through $\mathrm{CF}$ was significant $(\mathrm{b}=2.17 ; 95 \% \mathrm{CI}=1.42-2.93 ; \mathrm{p}<0.001)$. Wasting was directly and significantly associated with LBW $(b=1.49 ; 95 \% 0.39-2.58 ; \mathrm{p}=0.008)$. Family income at pregnancy indirectly and significantly affected the risk of wasting both through LBW and middle upper-arm circumference at pregnancy.

Conclusion: EBF and CF jointly predict the risk of wasting. Only if EBF is followed by CF, it can reduce the risk of wasting in children under five. LBW is a significant predictor of wasting.

Keywords: Wasting, Family income, Birthweight, Exclusive breastfeeding, Complementary feeding, Path analysis.

(C) 2018 The Authors. Published by Innovare Academic Sciences Pvt Ltd. This is an open access article under the CC BY license (http://creativecommons. org/licenses/by/4. 0/) DOI: http://dx.doi.org/10.22159/ajpcr.2018.v11i12.28068

\section{INTRODUCTION}

Wasting is one of the most important public health problems in the developing countries. Wasting, or low weight for height, is a strong predictor of mortality and morbidity among children under five [1,2]. Wasted children have a 5-20 times higher risk of dying from common diseases such as diarrhea or pneumonia than normally nourished children [3].

Aside from being a major risk factor for child mortality, childhood undernutrition has the long-term effects that include lower attained schooling, decreased economic potential, and chronic illness in adulthood [4]. Wasting prevalence in children under five was $10 \%$ or more in 24 countries, including almost all countries in South Asia and many in Sub-Saharan Africa in 2000-2006 [2]. Worldwide, 52 million children under five are wasted, and most of the global burden of wasting (acute undernutrition) is found in the developing countries [5].

The terms wasting and stunting were introduced in the early 1970 s by John Waterlow to differentiate, among underweight children, those who had a low weight in relation to their height (wasted) from those who were short for their age (stunted). In general, wasting is viewed to occur as a consequence of short-term response to inadequate intake or an infectious disease episode. Wasting can be caused by an extremely low energy intake, nutrient losses due to infection, or a combination of low intake and high loss. Wasting is associated with decreased fat mass. Fat secretes multiple hormones, including leptin, which may have a stimulating effect on the immune system. Depressed immunity resulting from low-fat stores may also contribute to the increased mortality observed in wasting. Wasting can be reversed if the child has access to adequate dietary intake in an environment that is free from infectious disease [6].

Numerous factors have been studied to contribute to the pattern of growth faltering in under-resourced settings, including inappropriate breastfeeding and infant and young child feeding practices, lack of adequate quality and amount of complementary foods, infection, and other environmental exposures [7,8]. Further, the first 1000 days of life (i.e., conception through 24 months of age) are well-recognized as a life-stage continuum between the fetal period and infancy and early childhood during which critical human growth and development occur. Fetal growth and birthweight as its culmination are likely to influence childhood growth [7].

However, few birth cohort studies have examined the associations between fetal growth along with contemporary risk factors and childhood wasting. Specifically, the effects of wasting related to low birthweight (LBW), exclusive breastfeeding (EBF), and complementary feeding (CF) practice have been rarely estimated. This study aimed to estimate the relationships between EBF, CF practice, and LBW and wasting, while controlling for some confounding factors, including maternal middle upper-arm circumference (MUAC) at pregnancy, and family income at pregnancy, using longitudinal data and path analysis.

\section{METHODS}

Study design

This was a case-control study conducted in Purworejo, Central Java, Indonesia, from February to March 2017. 
Population and sample

The target population was children between 2 and 5 years of age, while the accessible population was a subset of those children who lived in three subdistricts: Purworejo, Kaligesing, and Bruno, in Purworejo district, Central Java, Indonesia. The sampling frame was created based on data available at the adjacent Puskesmas (Community Health Centers) and District Health Office. A total sample of 160 children 2-5 years of age were selected for this study by fixed disease sampling [9] with case-control ratio of approximately 1:4. This sampling resulted in 28 wasted children and 132 normal weight children. Cases of wasted children were identified and selected from those visiting several Posyandu (i.e., family health posts). Posyandu is a regular community-based activities with a primary aim to monitor and deliver services of maternal and child health. Posyandu activities are jointly carried out by village health workers and formal health workers at hamlet level.

\section{Study variables}

The dependent variable was wasting. The independent variables were family income at pregnancy, MUAC, LBW, EBF, and CF.

Wasting was defined according to the World Health Organization (WHO) as having a weight-for-height of Z-score lower than two standard deviations (weight for height $\mathrm{z}$ [WHZ] <-2 SD) compared to the WHO reference population median of the same age and sex group [10,11]. Wasting was dummy coded as 0 (normal nutritional status) if $-2 \mathrm{SD} \leq$ $\mathrm{WHZ}<1 \mathrm{SD}$ and 1 (wasted) if $\mathrm{WHZ}<-2 \mathrm{SD}$.

CF was defined as the process starting when breast milk alone is no longer sufficient to meet the nutritional requirements of infants, and therefore, other foods and liquids are needed, along with breast milk. It is the transition from EBF to family foods, typically covers between 6 and 18-24 months of age $[10,12]$. In the present study, CF should be timely in that all infants should start receiving foods in addition to breast milk from 6 months onward. It should be adequate in that the complementary foods were given in amounts, frequency, consistency, and using a variety of foods to cover the nutritional needs of the growing child while maintaining breastfeeding. CF was dummy coded 0 if untimely or inadequate and 1 if timely and adequate.

EBF was defined as the infant receiving only breast milk, no other liquids or solids are given - not even water - with the exception of oral rehydration solution or drops/syrups of vitamins, minerals, or medicines, typically for the first 6 months of life [13]. EBF was coded 0 if no and 1 if yes.

LBW was defined according to the WHO as weight at birth of $<2500 \mathrm{~g}$, irrespective of the gestational age [14]. LBW was coded 0 (normal weight) if birthweight $\geq 2500 \mathrm{~g}$ and 1 (LBW) if birthweight $<2500 \mathrm{~g}$.

MUAC was defined as the circumference of the left upper arm, measured at the mid-point between the tip of the shoulder and the tip of the elbow (olecranon process and the acromium). MUAC was used for the assessment of maternal nutritional status [3]. MUAC was dummy coded as 0 if $<23.5 \mathrm{~cm}$ and 1 if $\geq 23.5 \mathrm{~cm}$.

\section{Data collection}

Data on child birthweight and maternal MUAC were obtained from maternal and child record. The data on the remaining variables were measured by pre-tested questionnaire.

\section{Data analysis}

The present study employed path analysis for data analysis. Path analysis is the statistical technique that allows an examination of causal relationships between one or more independent variables, either continuous or categorical, and one or more dependent variables, either continuous or categorical. It is a second-generation multivariate method (the first generation being multiple regression) based on a linear equation system and was first developed by Sewall Wright in the 1930s [15]. The path analysis was run using Stata 13 [16]
Path analysis proceeded in five steps: (1) Model specification; (2) model identification; (3) model fit; (4) coefficient estimates; and (5) model respecification (if necessary). In the present study, model specification was based on life-course theoretical conceptual framework coupled with sample data. Model identification assessed the adequacy of the sample size by calculating the degree of freedom (df), which was essentially comparing the number of measured variables on the one hand, and the number of endogenous variables, exogenous variables, and parameters to be estimated, on the other. By rule, sample size is adequate and a path analysis is appropriate to run if $\mathrm{df} \geq 0$. For a path analysis to be appropriate to execute, the sample size required is represented by the degree of freedom (df). That requires the total number of observed variables should exceed the total number of endogenous and exogenous variables and number of parameters to be estimated. The df should be positive or equal to zero, i.e. $\mathrm{df} \geq 0$. $\mathrm{Df}>0$ is called over-identified. $\mathrm{Df}=0$ is called just identified. The formula and calculation of $\mathrm{df}$ are as follows: $\mathrm{df}={ }^{\#}$ measured variables $-\left({ }^{\#}\right.$ endogenous ${ }^{\#}{ }^{*}$ exogenous $+^{*}$ parameter $)$.

\section{Research ethics}

This study received research ethics approval from the Ethics Health Research Commission of Dr. Moewardi Hospital/School of Medicine, Sebelas Maret University, Surakarta, No: 79/II/HREC/2017, on February 16, 2017. Information about the objective of the study, procedures, potential risks, and benefits was given to mothers before their children were enrolled in the study. Participation in the survey was voluntary, and participants' full right to refuse participation was explained.

\section{RESULTS}

\section{Univariate analysis}

Table 1 describes the characteristics the study population. The present study was not intended to describe the prevalence of wasting, but rather to analyze the determinants of wasting, which has an implication that the sampling approach is not necessarily random sampling. Instead, it aimed to estimate the effects of EBF, CF, and LBW, on the risk of child wasting. Accordingly, the sample was not intentionally selected at random as if the case of prevalence study, but rather by fixed-disease sampling [9]. Taken from the epidemiological method of sampling, by fixed disease

\section{Table 1: Sample characteristics}

\begin{tabular}{ll}
\hline Characteristics & n (\%) \\
\hline Children gender & \\
$\quad$ Male & $75(46.9$ \\
$\quad$ Female & $85(53.1)$ \\
Children age (month) & \\
$\quad<41$ & $72(45.9)$ \\
$\quad \geq 41$ & $85(53.1)$ \\
Maternal age at pregnancy (Years) & $133(83.1)$ \\
$\quad 20-<35$ & $27(16.9)$ \\
$\quad<20$ or $\geq 35$ & \\
Maternal MUAC at pregnancy & $49(30.6)$ \\
$\quad<23.5$ cm & $111(69.4)$ \\
$\geq 23.5$ cm & \\
Birthweight & $41(74.4)$ \\
$\quad$ Low birthweight $(<2500$ g) & $119(25.6)$ \\
$\quad$ Normoweight $(\geq 2500$ g) & \\
Family income (Rupiah) & $96(60)$ \\
$\quad<1,300,000$ & $64(40)$ \\
$\geq 1,300,000$ & \\
Exclusive breastfeeding & $54(33.8)$ \\
$\quad$ No & $106(66.3)$ \\
Yes & \\
Complementary feeding & $66(41.3)$ \\
Untimely or inadequate & $94(58.8)$ \\
Timely and adequate & \\
Child nutritional status & $132(82.5)$ \\
$\quad$ Normal &
\end{tabular}

MUAC: Maternal middle upper-arm circumference 
sampling, it means the researcher started to select study subjects based on the "disease status" (dependent variable), which is in the present study wasting versus normal. The "exposure status" (i.e. consisting of all independent variables under study) varies according to this wasting status. By fixed-disease sampling, it means that the study subjects were selected based on "disease status", in this instance the wasting status, as normally used in a case control study, with case: control ratio of approximately 1:4. The underlying reason for this is that the number of cases (wasting) in the population is small. Therefore, in order to obtain sufficient number of cases (wasting) and to have sufficient sample, the strategy that the researcher can take usually is to increase the number of controls (normal). As Table 1 has described, the resulting sample consisted of $28(17.5 \%)$ wasted children and 132 (62.5\%) normal children. As expected, the proportion of wasted children was $17.5 \%$, which should not be inferred as an estimated prevalence of wasting in the present target population. Likewise, theoretically wasting was expected to be correlated with birth weight, which was empirically evidenced to be the case in the present study, so the proportion of LBW in this sample was $74.4 \%$. Again, this proportion should not be inferred as an estimated prevalence of LBW in the present target population.

In this sample, the proportion of female children (53.1\%) slightly outnumbered male children (46.9\%). The majority (83.1\%) of maternal age at pregnancy was between 20 and 35 years, which was supposed to be the ideal reproductive age.

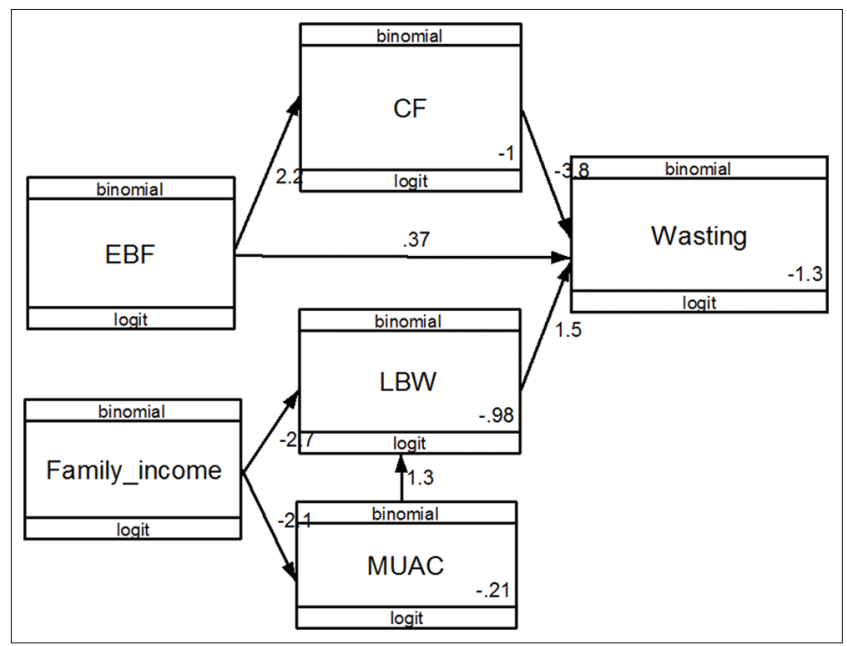

Fig. 1: Path analysis model on the effects of exclusive breastfeeding, complementary feeding, and low birthweight, on risk of wasting in children under five

\section{Path diagram}

Step 1 (model specification)

Fig. 1 depicts the final path analysis diagram on the direct and indirect factors associated with wasting, including CF, EBF, LBW, MUAC, and family income at pregnancy. This parsimonious model was developed on the basis of life-course theoretical conceptual framework coupled with sample data.

\section{Step 2 (model identification)}

df was calculated by comparing the number of measured variables $(\mathrm{k}=6)$, on the one hand, and the number of endogenous variables $(=4)$, exogenous variables $(=2)$, and parameters to be estimated $(=7)$, on the other hand. Df calculation was as follows:

$\mathrm{df}={ }^{\#}$ measured variables $-\left({ }^{\#}\right.$ endogenous ${ }^{\#}$ exogenous ${ }^{*}$ parameter $)$

$\mathrm{df}=[6(6+1)] / 2-[4+2+7]=8$

Since $\mathrm{df}=8>0$, it was overidentified and so path analysis was appropriate to perform.

\section{Step 3 (model fit)}

Log likelihood=-291.39 (Table 2). Log-likelihood, or the natural logarithm of likelihood, describes the plausibility of a model parameter value, given specific observed data. Log-likelihood values cannot be used alone as an index of fit because they are a function of sample size but can be used to compare the fit of different coefficients. The Maximum Likelihoodmethod of estimation employed in logistic regression as in this path analysis aimed to maximize the log-likelihood. The higher value is better than the lower. For example, a log-likelihood value of -3 is better than -7 [17]. In this sample data analysis, the log likelihood=-291.39, which was fairly low suggesting path model, was fairly fitted.

\section{Step 4 (coefficient estimation)}

Columns 1 and 2 of Table 2 show the dependent variable and the independents between which relationships were estimated in path analysis. By customary rule, the top-left panel of the table reports the independent variables that have direct effects on the dependent variable (e.g., wasting). The bottom-left panel of the table reports the independent variables that have indirect effects on the dependent variable. Next, column 3 of Table 2 shows the path coefficient estimate of each relationship. The sign of path coefficient indicates the direction of the effect, either increasing (+) or decreasing (-) the value of the dependent variable, or 0 indicating no effect (null hypothesis). The magnitude of the coefficient can be interpreted as in linear regression model. A path coefficient value of $b$ can be intrepreted as $b$ unit increase in the log odd of the dependent variable for every unit increase in the independent variable.

Table 2: Path analysis estimates of the direct and indirect effects of some independent variables on the risk wasting

\begin{tabular}{|c|c|c|c|c|c|c|}
\hline \multirow[t]{2}{*}{ Dependent variable } & & \multirow[t]{2}{*}{ Independent variable } & \multirow[t]{2}{*}{$\mathbf{b}$} & \multicolumn{2}{|l|}{$95 \% \mathrm{CI}$} & \multirow[t]{2}{*}{$\mathbf{p}$} \\
\hline & & & & Lower limit & Upper limit & \\
\hline \multicolumn{7}{|l|}{ Direct effect } \\
\hline Wasting & $\leftarrow$ & Complementary feeding & -3.65 & -5.72 & -1.59 & $<0.001$ \\
\hline Wasting & $\leftarrow$ & Low birthweight & 1.49 & 0.39 & 2.58 & 0.008 \\
\hline Wasting & $\leftarrow$ & Exclusive breastfeeding & 0.37 & -0.76 & 1.49 & 0.521 \\
\hline \multicolumn{7}{|l|}{ Indirect effect } \\
\hline Low birthweight & $\leftarrow$ & Maternal MUAC <23.5 cm & 1.26 & 0.43 & 2.08 & 0.003 \\
\hline Low birthweight & $\leftarrow$ & Family income at pregnancy & -2.66 & -4.15 & -1.17 & $<0.001$ \\
\hline Complementary feeding & $\leftarrow$ & Exclusive breastfeeding & 2.17 & 1.42 & 2.93 & $<0.001$ \\
\hline Maternal MUAC $\geq 23.5 \mathrm{~cm}$ & $\leftarrow$ & Family income at pregnancy & -2.06 & -2.99 & -1.13 & $<0.001$ \\
\hline \multicolumn{7}{|l|}{$\mathrm{N}$ observation $=160$} \\
\hline \multicolumn{7}{|l|}{ Log likelihood=-291.39 } \\
\hline \multicolumn{7}{|l|}{$\mathrm{AIC}=604.77$} \\
\hline $\mathrm{BIC}=638.60$ & & & & & & \\
\hline
\end{tabular}

MUAC: Maternal middle upper-arm circumference 
Since the dependent variable and all the independent variables were measured in dichotomous scale, essentially the magnitude of path coefficient indicates the effect on the log odd of the dependent variable for a change (departure) from the reference category of an independent variable to the other category of the same independent variable, while taking account of the effects of all other variables in the path model.

Table 2 shows that wasting was negatively and significantly associated with $\mathrm{CF}(\mathrm{b}=-3.65 ; 95 \% \mathrm{CI}=-5.72--1.59$; $\mathrm{p}<0.001)$. Literally, children who were complementary fed had the log odd of wasting 3.65 units lower than those were not. In other words, children who received CF were less likely to be wasted. Succintly, CF reduced the risk of wasting.

However, this good effect of $\mathrm{CF}$ on reducing the risk of wasting would only occur if it was preceded by EBF. There was a positive and statistically significant association between $\mathrm{CF}$ and EBF $(\mathrm{b}=2.17$; 95\% CI $=1.42-$ 2.93; $\mathrm{p}<0.001$ ). Literally, children who were previously breastfed had the log odd of being subsequently complementary fed 2.17 units higher than those who were not breastfed. In other words, children who were exclusively breastfed were more likely to be complementary fed.

On the other pathway, the direct association between wasting and EBF was not statistically significant $(b=0.37 ; 95 \% \mathrm{CI}=-0.76-1.49 ; \mathrm{p}=0.521)$. It seems that the good effect of EBF on reducing the risk of wasting would only occur if it was followed by CF. EBF was only effective when it went through subsequent CF. EBF was necessary but not sufficient to reduce the risk of wasting.

Findings from this study also highlight the importance of birth weight as a predictor of wasting. LBW was positively, directly, and significantly associated with the risk of wasting ( $b=1.49 ; 95 \% 0.39-2.58$; $p=0.008$ ). Children under five born with LBW were more likely to develop wasting compared with those with normal birthweight.

Finally, the results showed that family income at pregnancy had indirect but statistically significant association with the risk of wasting both through LBW and MUAC. Higher income decreased the risk of child being born LBW and increased the chance of mother having MUAC $\geq 23.5 \mathrm{~cm}$.

\section{DISCUSSION}

The main objective of the study was to estimate the relationships between EBF, CF practice, and LBW and wasting, while controlling for some confounding factors, including maternal MUAC, and family income at pregnancy, using longitudinal data and path analysis model. Several important findings emerged from this study.

\section{CF and wasting}

The present study supports the report of an earlier study that wasting is associated with deficiency of energy-dense nutrients in the diet [18]. The present study found that adequate $\mathrm{CF}$ was associated with reduced risk of child wasting $(b=-3.65 ; 95 \% \mathrm{CI}=-5.72--1.59 ; \mathrm{p}<0.001)$. This finding is consistent with an earlier study in Southwest China, which reported that CF frequency was significantly and positively associated with WHZ score among children aged 6-24 months, who were breastfed and given formula feeding $<3$ times per day, both in urban and rural areas [19].

The current study is also consistent with a cross-sectional study in Nigeria, which reported that children who did not receive timely complementary foods had higher odds for wasting (OR 5.15; 95\% $\mathrm{CI}=1.50-17.73$ ] [20]. Another cross-sectional study in urban Allahabad, India, also found that children under five who received improper $\mathrm{CF}$ were 1.5 times more likely to develop wasting compared with those received proper $\mathrm{CF}(\mathrm{OR}=1.50 ; 95 \% \mathrm{CI}=0.55-4.25)[21]$.

The present and previous studies add evidence that growth faltering (in term of wasting) can be prevented by adequate complementary food in terms of quality, quantity, and frequency of meals.

\section{EBF and wasting}

The present study did not find a significant and direct association between EBF and the risk of wasting ( $b=0.37$; 95\% $\mathrm{CI}=-0.76-1.49$; $\mathrm{p}=0.521$ ). However, it indeed was negatively, significantly, and indirectly, associated with the risk of wasting through its association with $\mathrm{CF}(\mathrm{b}=2.17 ; 95 \% \mathrm{CI}=1.42-2.93$; $\mathrm{p}<0.001)$. It means that $\mathrm{EBF}$ is only effective when it goes through subsequent $\mathrm{CF}$.

This finding runs the counter to the result of a cross-sectional study by Tariku et al. among aged 6-59 months in Northwest Ethiopia, which reported that late initiation of breastfeeding (AOR=1.43, 95\% CI: 1.04 , 1.95) was independently but weakly associated with wasting [8]. Two reasons might have resulted in these different outcomes. First, the present study employed multivariate path analysis that took account of mediating variables (so-called as endogenous variables), which assumed that the independent variable might have either a direct or indirect effect on the dependent variable, while the study by Tariku et al. employed multiple logistic regression, which assumed that all of the independent variables had direct effect on wasting. Second, both studies controlled for different confounding factors.

Finding of the present study, however, is consistent with an earlier study in India. It reported that EBF was not found a significant correlate of wasting, while this practice along with the timing of initiation of breastfeeding and age at introduction of CF was found to be significantly associated with wasting [21]. The present study and Kumar et al. share the common conclusion that EBF is only effective if it is followed by CF up to 2 years of age.

\section{LBW and wasting}

Path analysis of this study found that LBW was positively, significantly, and directly, associated with the risk of wasting ( $b=1.49$; 95\% 0.392.58; $\mathrm{p}=0.008$ ). Children under five with LBW were more likely to develop wasting compared to those with normal birthweight. This finding supports an earlier longitudinal birth cohorts among children 12-60 months of age, which reported that LBW was associated with 2.5-3.5-fold higher odds of wasting [7]

The present study is also consistent with Ghana Demographic and Health Survey that analyzed a data set consisted of 2720 pre-school children aged 0-59 months. By employing three-step moderated hierarchical multiple regression analyses, the authors reported that, compared to their counterparts who had normal birth weight $(\geq 2.5 \mathrm{~kg})$, children whose birth weight was $<2.5 \mathrm{~kg}$ were about 2.0 times (AOR=2.00; $95 \%$ $\mathrm{CI}=1.10-3.64$ ) more likely to be wasted, after adjusting for age of child, and household wealth index [4].

\section{Other correlates of wasting}

Numerous earlier studies have shown that malnutrition is an outcome of various factors resulting from unfavorable socioeconomic circumstances such as difficulties in obtaining food, unemployment which determines an irregular income for the family's breadwinner, limited access to education and health services, or illness caused by unsanitary conditions [22]. According to a report, around 1.3 billion population of the world survive in extreme poverty and dilapidated health [23]. A cross-sectional survey in Fars Province, Iran, reported that children under 6 years of age with the lowest family income quintile were 1.81 times $(\mathrm{AOR}=1.81 ; 95 \% \mathrm{CI}=0.83-3.93)$ more likely to be wasted, compared with counterparts with the highest family income quintile, although it was statistically non-significant [24].

The results of the present study add a life-course evidence that family income at pregnancy had indirect but statistically significant association with the risk of wasting both through LBW and MUAC. Higher income decreased the risk of a child being born LBW and increased the chance of mother having MUAC $\geq 23.5 \mathrm{~cm}$.

\section{CONCLUSION}

This case-control study has provided evidence from a life-course perspective using longitudinal data and path analysis model. It 
concludes that $\mathrm{EBF}$ and $\mathrm{CF}$ jointly in a sequential way predict the risk of wasting. Only if EBF is followed by CF, it can reduce the risk of wasting in children under five. LBW is a significant predictor of wasting, while LBW has its root cause in low family income at pregnancy.

Further studies are suggested to control for the effect of poor sanitation, either by considering its fixed effect in a path analysis model or alternatively by taking account of its random effect at a higher contextual level in a multilevel model. Poor sanitation is a risk factor of an infectious illness, which may cause nutrient depletion and eventually wasting in the affected children.

\section{AUTHORS' CONTRIBUTIONS}

Ika Yuli Ayuningrum raised the initial research question, managed data collection, ran statistical analysis, drew tables and graphs, and edited manuscript. Bhisma Murti refined research questions, planned study design, planned and ran statistical analysis, interpreted results, and wrote up manuscript. Harsono Salimo discussed and gave suggestion into this research from a pediatrician point of view. Yulia Lanti Retno Dewi checked anthropometric nutritional status and food intake measurement and discussed and suggested some nutritional issues.

\section{CONFLICTS OF INTEREST}

The authors certify that they have no affiliations with or involvement in any organization or entity with any financial interest or non-financial interest in the subject matter or materials discussed in this manuscript.

\section{REFERENCES}

1. World Health Organization, UNICEF, World Food Programme. Global Nutrition Targets 2025: Wasting Policy Brief; 2014. Available from: http://www.apps.who.int/iris/bitstream/handle/-10665/149023/WHO NMH NHD 14.8 engpdf;jsessionid =E8F5B5AFAD4CDBF149ECB 74E379B1183?sequence $=1$. [Last accessed on $2018 \mathrm{Jun}$ ].

2. UNICEF. Progress for Children: A World Fit for Children Statistical Review. UNICEF; 2018. Available from: https://www.unicef.org/ progressforchildren/2007n6/index41505.htm. [Last accessed on 2018 Jun].

3. The Mother and Child Health and Education Trust. Mother and Child; 2018. Available from: http://www.mother-childnutrition.org/earlymalnutrition-detection/detection-referral-children-with-acute-malnutrition/muac.htm. [Last accessed on $2018 \mathrm{Jun}$ ]

4. Saaka M, Galaa SZ. Relationships between wasting and stunting and their concurrent occurrence in ghanaian preschool children. J Nutr Metab 2016. DOI: org/10.1155/2016/4654920.

5. The World Bank. Levels and Trends in Child Malnutrition: UnicefWho-the World Bank Joint Child Malnutrition Estimates. Washington, DC: The World Bank; 2012.

6. Briend A, Khara T, Dolan C. Wasting and stunting - similarities and differences: Policy and programmatic implications. Food Nutr Bull 2015;36:S15-23.

7. Christian P, Lee SF, Angel MD, Adair LS, Arifeen SE, Ashornet P, et al. Risk of childhood undernutrition related to small-for-gestational age and preterm birth in low-and middle-income countries. Int J Epidemiol 2013;42:1340-55.
8. Tariku A, Bikis GA, Woldie H, Wassie MM, Worku AG. Child wasting is a severe public health problem in the predominantly rural population of ethiopia: A community based cross-sectional study. Arch Public Health 2017;75:26.

9. Murti B. Prinsip dan Metode Riset Epidemiologi. Surakarta: Program Studi ilmu Kesehatan Masyarakat, Program Pascasarjana, Universitas Sebelas Maret; 2018.

10. World Health Organization. Nutrition Landscape Information System (NLIS)-Country Profile Indicators Interpretation Guide. Geneva: WHO; 2010. Available from: http://www.apps.who. int/iris/bitstream/handle/10665/44397/9789241599955_eng. pdf? sequence $=1 \&$ isAllowed=y. [Last accessed on 2018 Jun 20].

11. World Health Organization. Training Course on Child Growth Assessment. WHO Child Growth Standards. Interpreting Growth Indicators. Department of Nutrition for Health and Development. Geneva: World Health Organization; 2008.

12. PAHO. Guiding Principles for Complementary Feeding of the Breastfed Child. Washington, DC: Pan American Health Organization; 2003.

13. World Health Organization. Exclusive Breastfeeding for Optimal Growth, Development and Health of Infants; 2018. Available from: http://www.who.int/elena/titles/exclusivebreast-feeding/en/in. [Last accessed on 2018 Jun].

14. United Nations Children's Fund (UNICEF) and World Health Organization (WHO). Low Birthweight: Country, Regional and Global Estimates. New York: United Nations Children's Fund (UNICEF) and World Health Organization (WHO); 2004.

15. Crow JF. Sewall Wright 1889-1988. Washington, DC: National Academy of Science; 1994

16. StataCorp LLC. Structural Equation Modeling (SEM). StataCorp LLC; 2018. Available from: https://www.stata.com/features/structuralequation-modeling/. [Last accessed on 2018 Jun].

17. Minitab 18 Support. What is Log-Likelihood? Minitab, Inc.; 2017. Available from: https://www.support.minitab.-com/en-us/minitab/18/ help-and-how-to/modeling-statistics/regression/supporting-topics/ regression-models/what-is-log-likelihood/. [Last accessed on 2018 Jun].

18. Pingale S, Patil VW, Patil S. Estimation of stunted, wasted, wasted and stunted children at town Dhadgaon, district-Nandurbar of Maharashtra State, India. Int J Pharm Pharm Sci 2013:7:529-31.

19. Zhou L, Li M, Pang X, Rui L, Sun X, Huang L, et al. Association between complementary feeding frequency and growth of infants and young children aged 6-24 months old in urban and rural areas of southwest China. Wei Sheng Yan Jiu 2014;43:541-5.

20. Udoh EE, Amod OK. Complementary feeding practices among mothers and nutritional status of infants in Akpabuyo Area, Cross River State Nigeria. Springerplus 2016;5:2073

21. Kumar D, Goel NK, Mittal PC, Misra P. Influence of infant-feeding practices on nutritional status of under-five children. Indian J Pediatr 2006;73:417-21.

22. Reyes H, Pérez-Cuevas R, Sandoval A, Castillo R, Santos JI, Doubova SV, et al. The family as a determinant of stunting in children living in conditions of extreme poverty: A case-control study. BMC Public Health 2004:4:57.

23. Gupta A. Assessing stunting and predisposing factors among children. Asian J Pharm Clin Res 2017;10:364-71.

24. Kavosi E, Rostami ZH, Kavosi Z, Nasihatkon A, Moghadami M, Heidari M. Prevalence and determinants of under-nutrition among childrenunder six: A cross-sectional survey in Fars province, Iran. Int J Health Policy Manag 2014;3:71-6. 